\title{
Article
}

\section{A New Dual Polarity Direct AC-AC Voltage Regulator Ensuring Voltage Step-Up and Step-Down Capabilities}

\author{
Naveed Ashraf ${ }^{1}$, Ghulam Abbas ${ }^{1, * \mathbb{C}}$, Nasim Ullah ${ }^{2}{ }^{\circledR}$, Ali Nasser Alzaed ${ }^{3}$, Ali Raza ${ }^{4}($, \\ Muhammad Taskeen Raza ${ }^{5}$ and Umar Farooq ${ }^{6}$ (D)
}

1 Department of Electrical Engineering, The University of Lahore, Lahore 54000, Pakistan; naveed.ashraf@ee.uol.edu.pk

2 Department of Electrical Engineering, College of Engineering, Taif University, Taif 21944, Saudi Arabia; nasimullah@tu.edu.sa

3 Department of Architecture Engineering, College of Engineering, Taif University, P.O. Box 11099, Taif 21944, Saudi Arabia; alzaed@tu.edu.sa

4 Department of Electrical Engineering, University of Engineering and Technology, Lahore 54000, Pakistan; a.raza@uet.edu.pk

5 Department of Electrical Engineering, Lahore College for Women University, Lahore 54000, Pakistan; mtaskeenraza@gmail.com

6 Department of Electrical Engineering, University of the Punjab, Lahore 54590, Pakistan; engr.umarfarooq@yahoo.com

* Correspondence: ghulam.abbas@ee.uol.edu.pk

Citation: Ashraf, N.; Abbas, G.; Ullah, N.; Alzaed, A.N.; Raza, A.; Raza, M.T.; Farooq, U. A New Dual Polarity Direct AC-AC Voltage Regulator Ensuring Voltage Step-Up and Step-Down Capabilities. Appl. Sci. 2021, 11, 11944. https://doi.org/ 10.3390/app112411944

Academic Editor: Alfio Dario Grasso

Received: 7 November 2021

Accepted: 13 December 2021

Published: 15 December 2021

Publisher's Note: MDPI stays neutral with regard to jurisdictional claims in published maps and institutional affiliations.

Copyright: (c) 2021 by the authors. Licensee MDPI, Basel, Switzerland. This article is an open access article distributed under the terms and conditions of the Creative Commons Attribution (CC BY) license (https:// creativecommons.org/licenses/by/ $4.0 /)$.
Abstract: The problem of voltage sag and swell is one of the major reasons for low-quality power in the distribution system. Normally, it results from the system's faults, including line-to-ground and line-to-line, non-linear characteristics of loads and sources. Its effect is very serious for the critical loads as their performance is very sensitive to the variation in voltage. The stabilization of voltage is a mandatory requirement in such a situation. The correction of such problems requires the addition and subtraction of the voltage once the line voltage is decreased and increased. This behavior of the correcting voltage is ensured by the use of voltage controllers that can convert a constant input voltage into a non-inverted and inverted variable form. Their voltage gains depend on the depth level of the problem. The voltage buck and boost capabilities of the AC voltage stabilizers can tackle the problems having any depth level. The smartness of such a system depends on the number of electronic devices as they are the key elements in the power conversion system. Therefore, this research proposes a new AC voltage controller with fewer solid-state devices. Its overall impact is low volume and cost. The validation of the introduced approach is ensured with the help of simulation modeling and results gained from the practical setup.

Keywords: AC voltage controller; buck and boost; critical loads; electronic devices; inverted and non-inverted outputs; power quality; power conversion; voltage sag and swell

\section{Introduction}

The development in solid-state electronics is playing a major contribution to the development of modern society. However, the operation of these pieces of equipment is very sensitive to variation in the supplied voltage $[1,2]$. The main source of their incorrect outputs is the decrease and increase in values of the supplied voltage. In power quality terminology, this problem is regarded as voltage sag if the line rms voltage is reduced $(80 \%$ to $20 \%$ ) with respect to nominal rated rms values during some input voltage cycles [3]. This situation requires the addition of voltage in the line that may achieve with the non-inverted output of the voltage stabilizers. The other type of voltage variation is characterized as voltage swell in which the line rms voltage is boosted to $110 \%$ to $180 \%$ of its normal rated value for a few milliseconds [4]. The correction of this situation requires injecting the voltage of opposite polarity of the line that can obtain from the inverted output of the 
voltage controllers. These problems are very frequent and challenging in power distribution systems during fault conditions $[5,6]$. For example, once there is a line-to-ground fault, the faulty line faces voltage sag while other phases experience a voltage swell problem. They may be resolved by adding and subtracting the voltage generated by the voltage controllers. The magnitude of the correcting voltage may be less than the voltage of the faulty phase if the depth level of the voltage variation is less than $50 \%$, which requires the voltage buck characteristics of the generated voltage. On the other side, it requires the voltage boost feature if the required level of the correcting voltage is more than $50 \%$. Therefore, voltage buck and boost features with dual polarities are a mandatory requirement of the correcting voltage for any depth level problem.

The traditional way to resolve these issues is the use of indirect approaches of AC-AC conversion [7-10]. That requires power conversion in two stages where a DC-link capacitor is a mandatory requirement between the two converters. Here at the front stage, a lowfrequency rectifier circuit transforms AC power to DC power to store in a DC-link capacitor. This stage may be a controlled rectifier if regulation of voltage at the DC-link level is required. This control highly decreases the power quality of input current that can only be tackled using harmonic suppression filters or complex switching arrangements. The second converting stage is responsible for DC to AC conversion, and once again, a complex control arrangement is required to tackle the low power quality. The other approach to address and tackle the low power quality issues is the execution of power conversion in multistage [8] or multilevel configuration $[9,10]$. This overall arrangement is complicated to realize, and DC-link capacitors are a big source of poor system reliability [11]. This approach is not feasible or smart for applications where only voltage control is essential at source frequency.

The direct AC-AC conversion is a smart solution for stabilizing the line voltage as it is realized without a DC-link capacitor. This solution approach is simple, less complex, and implementable in a single stage. So, it gains more attention from the researchers and developers. Thyristor-based AC voltage controllers (on-off or phase-angle) have some potency for low power application as the generated harmonics are always low frequency and have very severe power quality-related issues [12]. AC voltage controller based on high-frequency pulse-width modulation (PWM) control can be employed to tackle the low power quality concerns but their voltage gain is low (less than one) with unipolar capabilities. The voltage stabilization characteristics in direct AC-AC converters may be realized with the similar approach as adopted in direct DC-DC converters just with the replacement of unidirectional operating semiconductor devices with bidirectional devices as proposed in [13]. The converters based on this approach mentioned in [1,13] have positive or negative voltage gain, so they can only address either voltage sag or swell issue.

The direct AC-AC converters reported in [14-16] use a z-source structure to ensure the dual polarity voltage. This structure also facilitates tackling the shoot-through challenge of the complementary operated switching devices. Z-source structure is a specific arrangement of many inductors and capacitors that not only result in large size or cost but also it is a big source of slow system's dynamic behavior. The deficiencies resulting from these power converting approaches are tackled with other AC-AC techniques applied in non-z-source structures as reported in [17-20]. The converter employed with the structure reported in [3] has bipolar voltage buck characteristics, and its application is only limited to the compensation of the low depth level power quality issues. Conversely, the voltage controllers as applied in [4] have only voltage boosting features. It can only tackle the power quality problem where the voltage correcting level is more than $50 \%$. These stated voltage controllers lack the compensation for all depth level problems required for reliable operation in the power system.

Voltage buck and boost operation ensure the generation of correcting voltage for any depth level problem. Such voltage compensating techniques are addressed in $[19,20]$. The power converters, as stated in [19], can generate correcting voltage with any polarity but its operation is only limited to voltage buck-boost capabilities. This circuit has many serious 
power quality concerns, such as a high ripple in the inductor current and output capacitor voltage. Furthermore, a high value of operating current and break-over voltage is the main source of high losses. It also increases the power rating of solid-state devices. The buck and boost operation rather than buck-boost can be employed to address these concerns. One of such approaches as illustrated in Figure 1 is stated in [20]. The realization of this approach requires the use of eight high switching diodes and eight metal-oxide field-effect transistors (MOSFETs). Each diode and MOSFET form a pair that converts the bidirectional current conduction characteristics of a MOSFET into unidirectional. These current conduction capabilities block the conduction of the MOSFET's body diode that has very slow reverse characteristics. This arrangement also ensures the elimination of the shoot-through issue that avoids the current interruption of the inductor. The main issue of such topology is the use of a large number of diodes and especially transistors. The on and off control of a transistor is a big challenge, especially once it is connected to a high voltage side (a situation in which the reference terminal of the transistor is not connected to the reference point of the circuit). Switching of transistors (MOSFETs) in such circumstances requires the use of a reliable gate supporting circuit. This circuit may be implemented with a number of passive components, microelectronic devices, and separate isolated DC sources. This arrangement increases the volume and cost of the overall system as the size of the gate operating circuit is always much larger than the operating transistor. There are also some associated control circuit losses as addressed in [21,22].

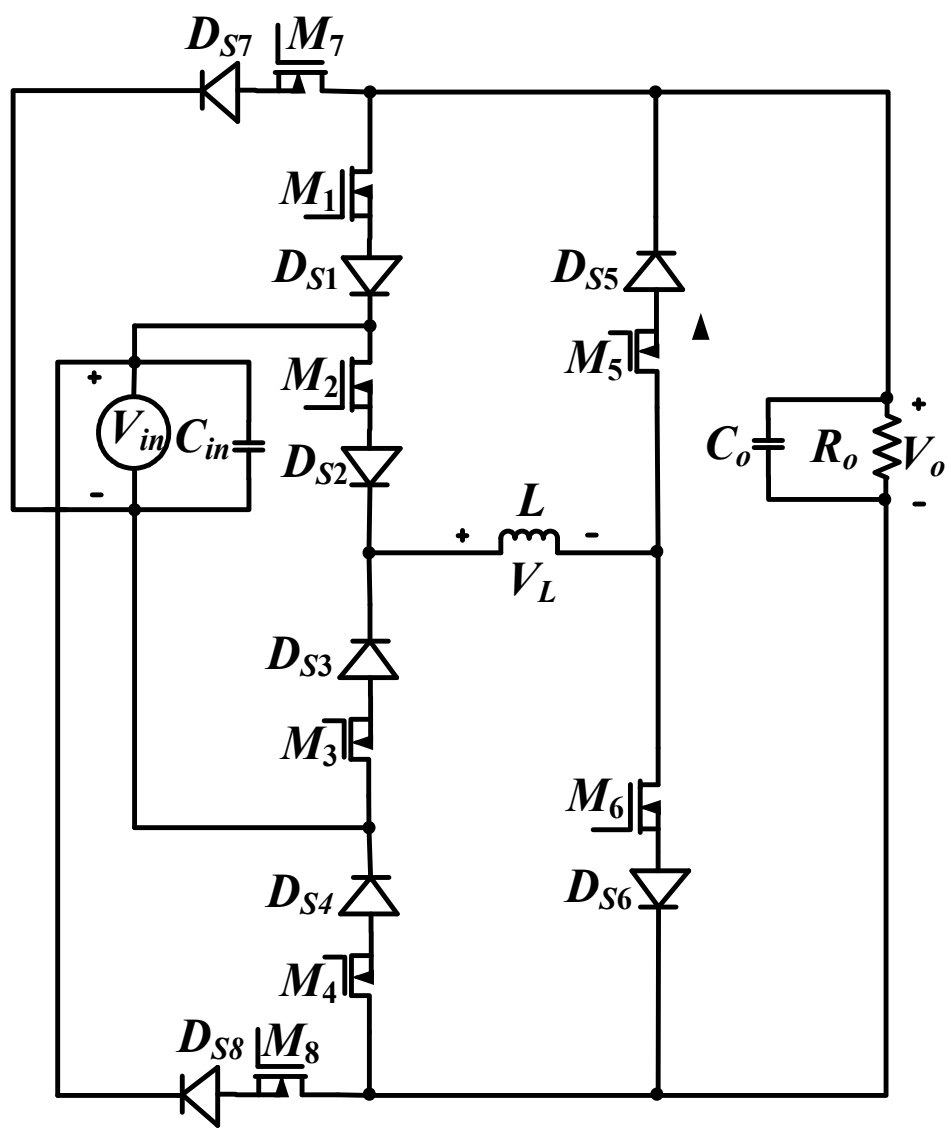

Figure 1. Buck-boost voltage controller reported in [20].

In keeping these constraints, we have eliminated the use of two diodes and two transistors in our newly developed power converting approach that can generate the same outputs as obtained in [20]. The reduction of two transistors compacts the size of the converter as there is the elimination of two gate operating circuits and two separate isolated DC sources. This overall arrangement lowers the size, cost, and losses of the system. 
The rest of the arrangement of this article includes the introduction of the proposed topology and its operating modes in Section 2. Here the relation of output voltage to the input voltage is correlated with the help of inductor voltage. The conversion losses are discussed in Section 2. Section 4 compares the performances of the developed converter. Section 5 explores the design of the filtering components. The result obtained by simulation modeling and practical prototypes are illustrated in Section 6. The conclusion is stated in Section 7.

\section{Operating Principle and Modes}

This section describes the working principle and all possible operational modes of the proposed converter in some detail. The developed circuit shown in Figure 2 is composed of six high-frequency diodes $\left(D_{1}\right.$ to $\left.D_{6}\right)$ and six transistors ( $T_{r 1}$ to $\left.T_{r 6}\right)$. This circuit is a modified form of the circuit presented in [23], where the voltage step-down capabilities are enhanced by adding two more switching transistors $\left(T_{r 1}\right.$ and $\left.T_{r 3}\right)$. These transistors are used to convert the constant sinusoidal voltage of the input to its controllable absolute form through PWM control. In any of the operating intervals of the developed circuit, one transistor and one diode operate at high frequency along with the low frequency (input or output frequency) operation of two transistors and diodes. So, there is always the conduction of three diodes and transistors [11,20]. There is also the use of one inductor $(L)$ and two capacitors (one for input $\left(C_{i n}\right)$ and the other for output $\left(C_{\text {out }}\right)$ to tackle the power quality issues. The series connection of diode and transistor forms pairs $D_{1}-T_{r 1}, D_{3}-T_{r 3}$, $D_{5}-T_{r 5}$ and $D_{6}-T_{r 6}$. This makes sure the elimination of shoot-through owing to the parallel connection of input and output capacitors, shorting of input or output capacitors. As an example, the connection of diodes $D_{1}$ and $D_{3}$ avoids the possibility of the direct parallel connection of input and output capacitors. The use of an intermediate inductor avoids the shorting of the input source or capacitor during the situation in which all transistors remain on. This situation may be possible due to the defects in the manufacturing process of the transistors or incorrect control inputs. This problem is normally faced when two transistors must turn on and off in a complementary way. There may be a possibility that turning off transistor may turn off later than turning on transistor. Similarly, the series connection of $D_{5}-T_{r 5}$ and $D_{6}-T_{r 6}$ prevents the shorting of the output capacitor. The details of the operation in dual polarity voltage step-down and step-up modes are explained here with the help of mathematical equations and circuit loops.

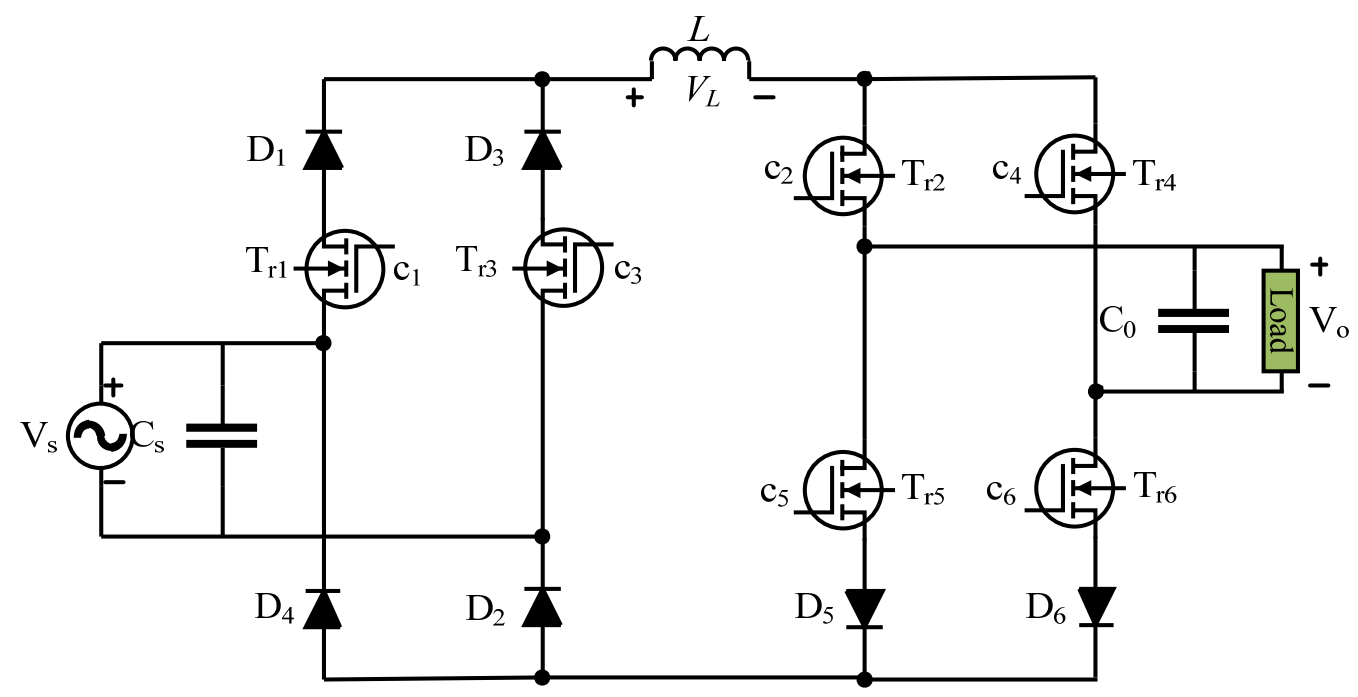

Figure 2. Proposed circuit.

The control strategy shown in Figure $3 a, b$ to turn on and off the transistors for noninverting and inverting voltage buck operation, respectively, is almost the same as ex- 
plained in [20]. Here all the generated control signals follow the variation in the polarity of the input voltage. For this purpose, the input voltage polarity sensing circuit generates high $(5 \mathrm{~V})$ and low $(0 \mathrm{~V})$ outputs indicating positive and negative input values, respectively. As an example of voltage step-down operation for both polarities of the output voltage (inverting and non-inverting outputs), the PWM control signals $c_{1}$ and $c_{3}$ shown in Figure $3 \mathrm{a}, \mathrm{b}$ are responsible for power conversion with voltage buck capabilities during the positive and negative input. So, the variation in the instantaneous output voltage is obtained by the high-frequency PWM switching of the transistors $T_{r 1}$ and $T_{r 3}$ during positive and negative input values, respectively. Here the role of the front-end circuit is to convert the constant sinusoidal input voltage into its regulated absolute form. The control of non-inverting and inverting output buck operation is determined from the low-frequency switching operation of the transistors employed in the second stage circuit. For this purpose, the remaining four control signals $c_{2}, c_{6}$ and $c_{4}, c_{5}$ shown in Figure 3a have logic high and low values throughout the intervals in which input is positive and negative, respectively. It should be noted that control signals $c_{4}$ and $c_{5}$ are generated in the complementary form of $c_{2}$ and $c_{6}$. The same control scheme can effectively be employed for an inverting buck operation of the output voltage. It is clear from Figure $3 b$ that there is no change in the control signal $c_{1}$ and $c_{3}$ as their role is the same as in non-inverting operation that is to convert the constant sinusoidal input voltage to its controllable absolute value. Here, like a non-inverting operation, the operating states of transistor $T_{r 2}, T_{r 6}$ and $T_{r 4}, T_{r 5}$ realize the inverting output. This task is obtained by reversing the switching states of the control signals $c_{r 2}, c_{r 6}$ and ${ }_{\mathrm{cr} 4}, c_{r 5}$ with respect to their values of non-inverting operation.

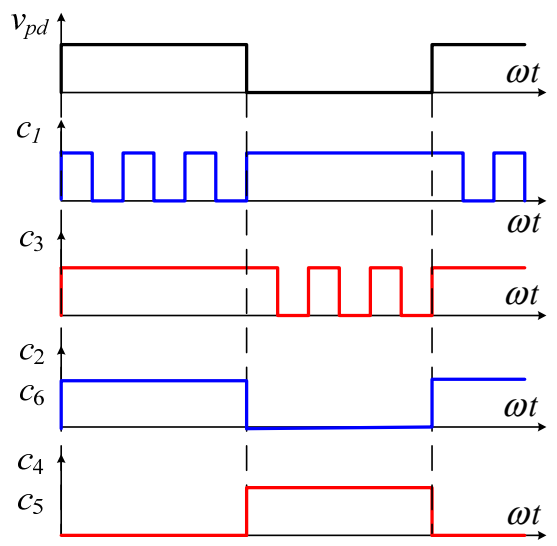

(a)

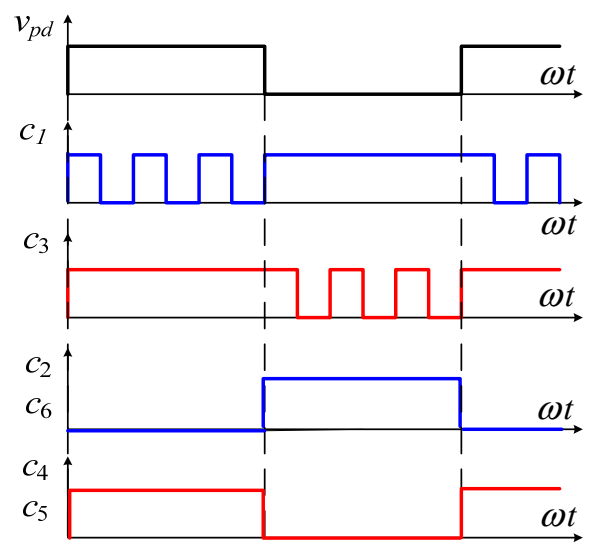

(b)

Figure 3. Generation of control signals with respect to input voltage polarity detector for voltage buck to achieve (a) noninverted form of output and (b) inverted form of output.

The role of control signals used for voltage buck operation is changed for non-inverting and inverting voltage boost operation. Still, the generated characteristics remain unaltered, as shown in Figure 4a,b. Here the PWM control of the transistors $T_{r 1}$ and $T_{r 3}$ is shifted to $T_{r 5}$ and $T_{6}$. Now, transistors $T_{r 1}$ and $T_{r 3}$ operate at low input frequency and ensure their on-states for positive and negative input voltage, respectively. For non-inverting and inverting voltage boost operation, the role of the front stage circuit is only to transform the constant voltage sinusoidal input to its absolute form. This feature of the operation may be confirmed from the plots of Figure $4 \mathrm{a}, \mathrm{b}$ There is no change in states of the control signals $c_{1}$ and $c_{3}$ for the operation in which the output voltage is a non-inverted or inverted form of the input voltage. The inverted and noninverted form of the output depends on switching states of $c_{2}, c_{4}$ and $c_{5}, c_{6}$. The switching state of the control signals $c_{6}$ is swapped with $c_{5}$ and $c_{4}$ is swapped with $c_{2}$ once the output is changed from non-inverting to inverting boost form and vice versa. 


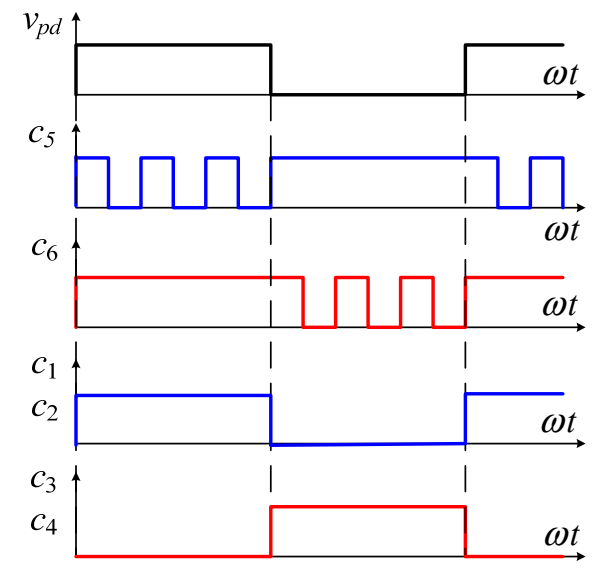

(a)

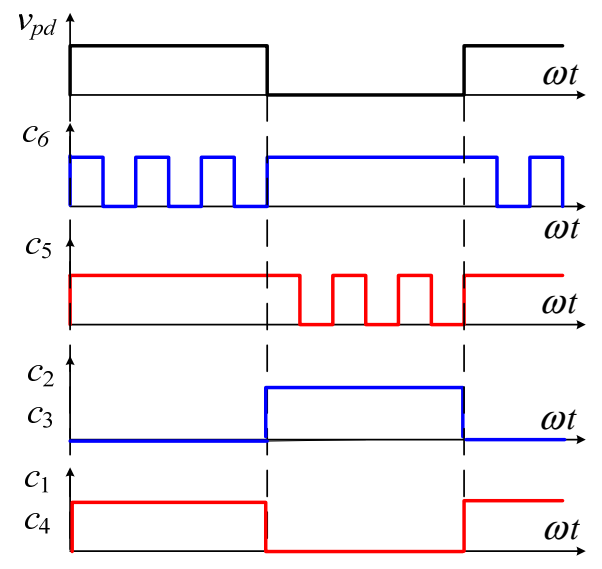

(b)

Figure 4. Generation of control signals with respect to input voltage polarity detector for voltage boost to achieve (a) noninverted form of the output and (b) inverted form of the output.

\subsection{Non-Inverting and Inverting Buck Operation}

This section provides detail on how the rms value of the input voltage at the output is regulated in voltage step-down capabilities with PWM control. Here the output rms voltage is adjusted from the maximum value of the input rms to some lower value. This task is achieved with PWM control of the switching transistors $T_{r 1}$ and $T_{r 3}$ for positive and negative input, respectively. The low frequency (input or output) operation of transistors $T_{r 2}, T_{r 4}, T_{r 5}$ and $T_{r 6}$ is responsible for in-phase or out-phase outputs. The circuits of Figure 5 comprehensively illustrate the voltage step-down operation indicating how the input power is supplied to load. Figure 5a-d show the power transferring loops for non-inverted output for positive and negative half-cycles input voltage, respectively.

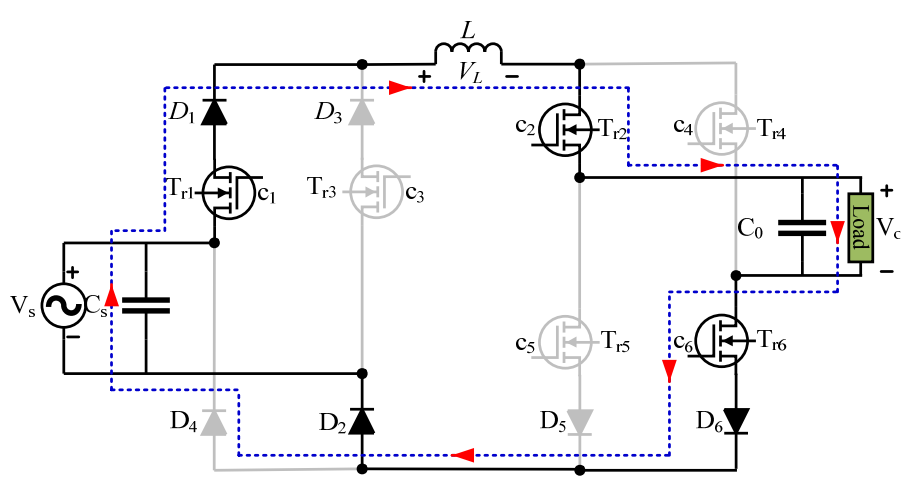

(a)

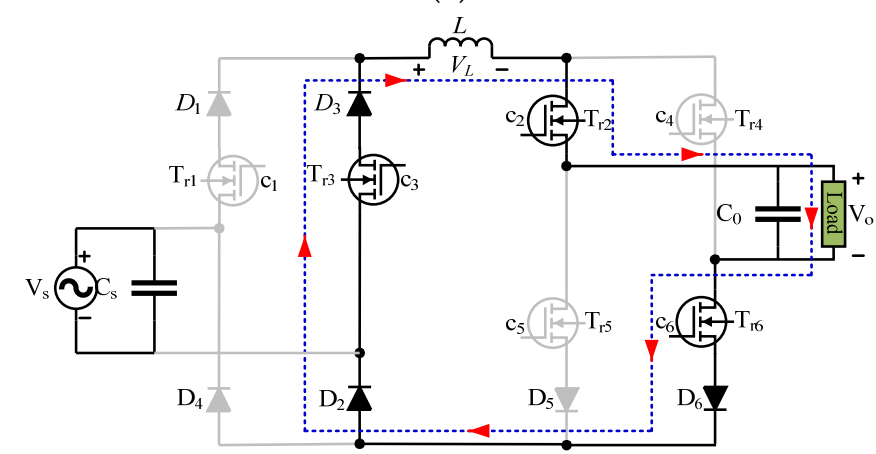

(c)

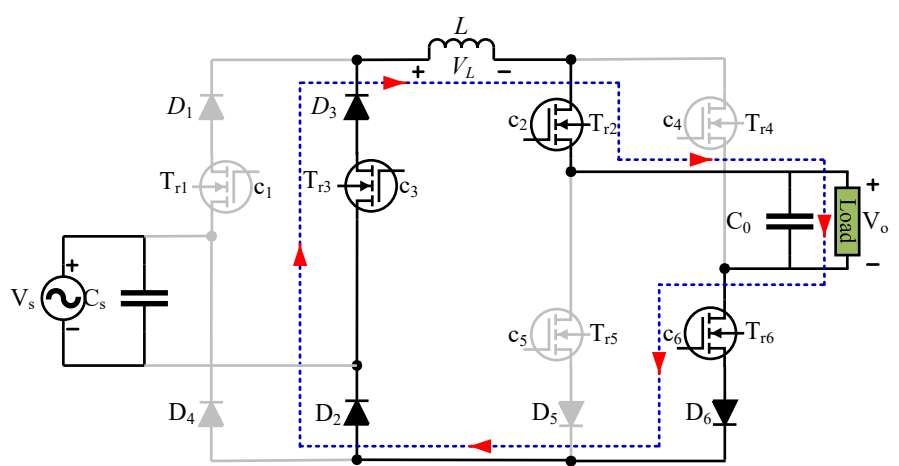

(b)

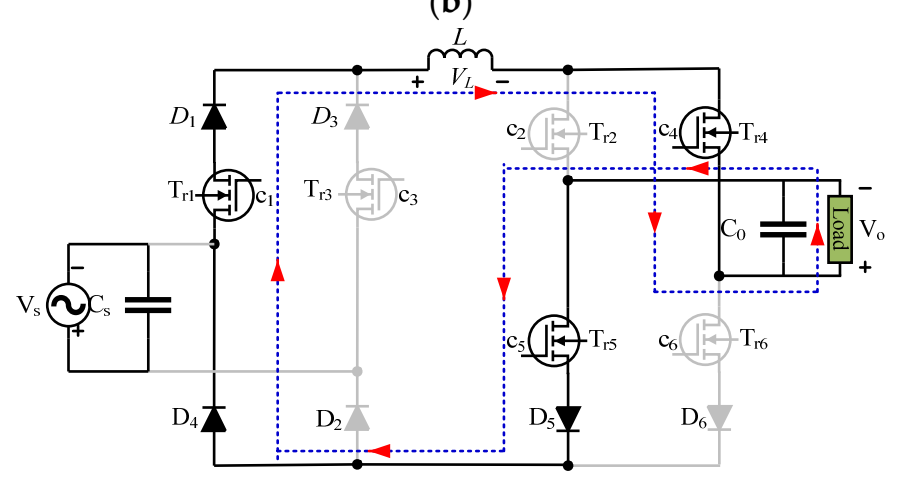

(d)

Figure 5. Equivalent power transfer loops formed by PWM control to have non-inverted voltage buck output for half-cycles of $(\mathbf{a}, \mathbf{b})$ positive source voltage; $(\mathbf{c}, \mathbf{d})$ negative source voltage. 
For positive input, the on-state role of the semiconductor devices $T_{r 1}, D_{1}, T_{r 2}, T_{r 6}, D_{6}$, and $D_{2}$ facilitate the power flow from source to load. The voltage drop across the inductor during the conducting interval $\left(t_{c}\right)$ of the PWM signal is the difference of the input and output voltage as observed in Equation (1).

$$
V_{L}\left(t_{c}\right)=V_{s}-V_{o}
$$

The turning on of the transistor $T_{r 3}$ facilitates the continuous conduction of inductor current as the reverse bias diode $D_{3}$ turns on in the non-conducting interval $\left(t_{n c}\right)$ of the PWM signal. During this interval, the absorbed power of the inductor is supplied to load, as may be found from the power supply loop of Figure $5 \mathrm{~b}$. Now the value of the inductor voltage is changed to output voltage level $V_{0}$.

$$
V_{L}\left(t_{n c}\right)=-V_{o}
$$

A similar analysis may be used to express the voltage buck operation for negative input and determine the value of inductor voltage during conducting and non-conducting PWM intervals. Figure $5 \mathrm{c}$ expresses the power supply path from source to load via the conduction of $T_{r 3}, D_{3}, T_{r 4}, D_{4}, T_{r 5}$, and $D_{5}$. The continuous conduction of inductor current is confirmed by maintaining the transistor $T_{r 1}$ in conducting state because the diode $D_{1}$ is only reverse biased as long as $T_{r 3}$ is on. The transfer of the inductor's stored power is recovered by the conduction of $T_{r 1}, D_{1}, T_{r 4}, D_{4}, T_{r 5}$, and $D_{5}$, as expressed in Figure $5 \mathrm{~d}$. The realization of the inductor voltage during the conducting and non-conducting interval is accomplished as

$$
\begin{gathered}
V_{L}\left(t_{c}\right)=V_{s}-V_{o} \\
V_{L}\left(t_{n c}\right)=-V_{o}
\end{gathered}
$$

The values of these voltages may be regarded as constant as the selected switching frequency is much higher (for example, $25 \mathrm{kHz}$ ) than the input or output frequency $(50 \mathrm{~Hz})$. The average value of the inductor voltage in the steady-state condition in one switching interval is always zero, and this result may be utilized to find the relation of output voltage with respect to the input voltage. Here $D$ and $T$ are the duty ratio and the period of the PWM signal, respectively.

$$
V_{L(\operatorname{avg})}=\frac{L}{T}\left\{i_{L}(T)-i_{L}(0)\right\}=0
$$

This implies that in a switching interval $(T)$, the inductor volt-second product is zero. For non-inverting voltage buck operation with any polarity of the input voltage, we get

$$
V_{L}\left(t_{c}\right)=V_{s}-V_{o} V_{L}\left(t_{n c}\right)=-V_{o}
$$

so

$$
\begin{gathered}
\left(V_{s}-V_{o}\right) t_{c}-V_{o} t_{n c}=0 \\
V_{s} t_{c}=V_{o}\left(t_{c}+t_{n c}\right) \\
V_{s} D T=V_{o} T \\
V_{o}=D V_{s}
\end{gathered}
$$

By employing a similar methodology, the voltage step-down inverting behavior of the proposed circuit can also be validated with equivalent circuits and mathematical equations. This mode produced an inverted form of the input voltage at the output, and this is simply turning on the low-frequency transistors $T_{r 4}, T_{r 5}$ and $T_{r 2}, T_{r 6}$ for positive and negative input voltage by maintaining the switching role of $T_{r 1}$ and $T_{r 3}$ unchanged. The power transfer loops of Figure 6a-d explain how the variable inverting outputs with voltage buck capabilities are obtained from a constant input voltage. 


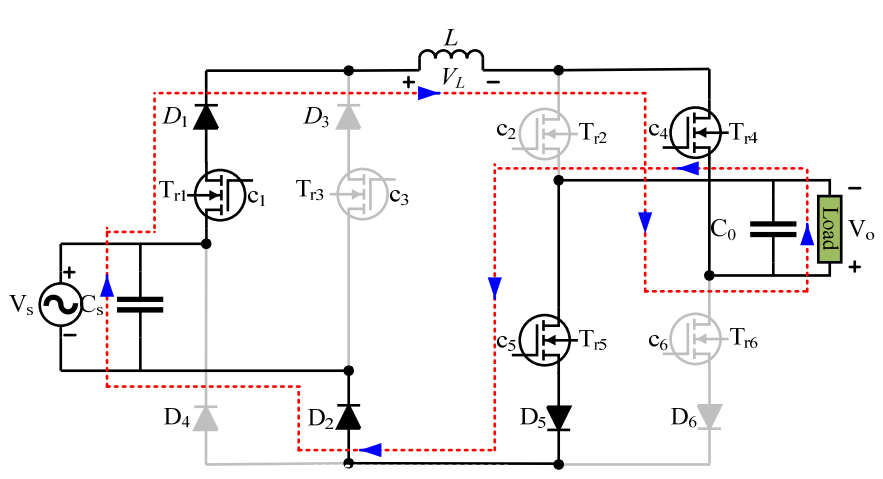

(a)

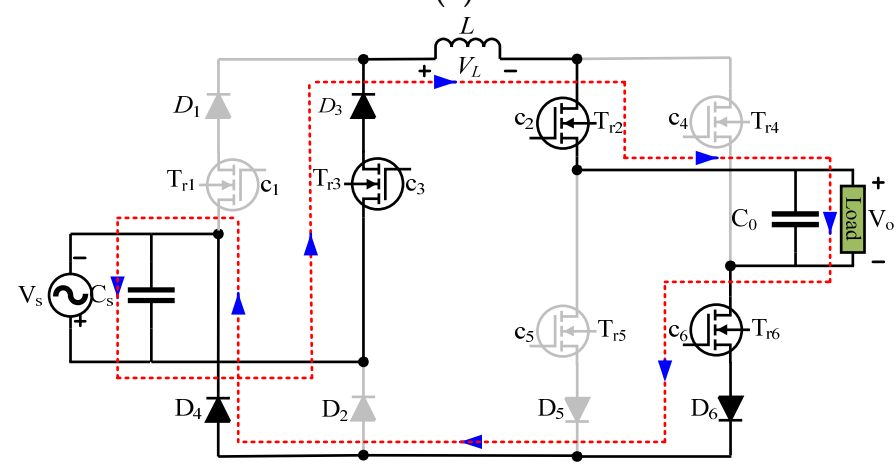

(c)

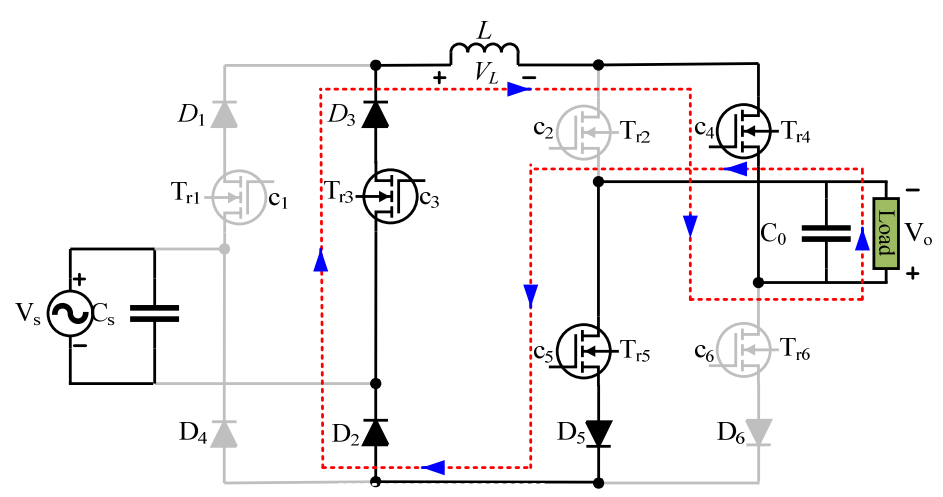

(b)

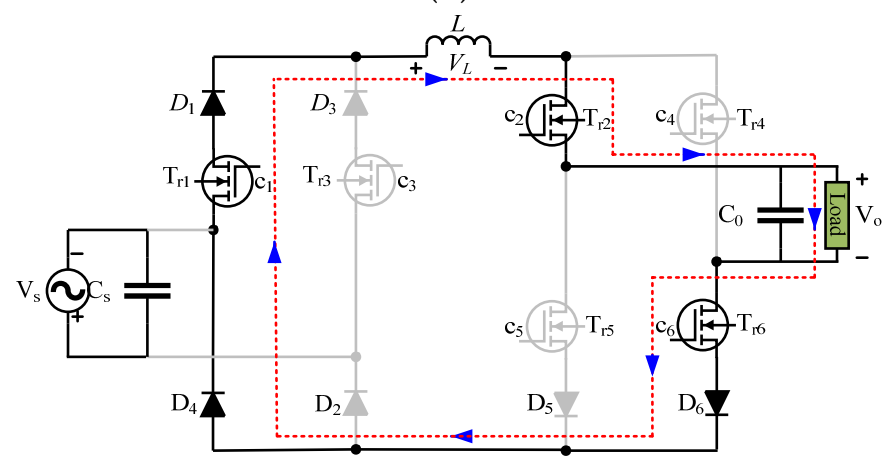

(d)

Figure 6. Equivalent power transfer loops formed by PWM control to have inverted voltage buck output for half cycles of $(\mathbf{a}, \mathbf{b})$ positive source voltage; $(\mathbf{c}, \mathbf{d})$ negative source voltage.

The mathematical validation of this behavior can be proved by employing a similar approach as used for a non-inverting buck operation. The value of the inductor voltage during the conducting and non-conducting interval for any value of the input voltage may be depicted as

$$
\begin{gathered}
V_{L}\left(t_{c}\right)=V_{s}+V_{o} \\
V_{L}\left(t_{n c}\right)=V_{o}
\end{gathered}
$$

Average inductor voltage gives

$$
\begin{gathered}
\left(V_{s}+V_{o}\right) t_{c}+V_{o} t_{n c}=0 \\
V_{s} t_{c}=-V_{o}\left(t_{c}+t_{n c}\right) \\
V_{s} D T=-V_{o} T \\
V_{o}=-D V_{s}
\end{gathered}
$$

The results of Equations (10) and (16) validate the voltage non-inverting and inverting buck operation, indicating that output is always controllable with the PWM control.

\subsection{Non-Inverting and Inverting Boost Operation}

The operation in this mode helps to increase the voltage of any polarity at the output with respect to the input voltage, and this voltage stabilization depends on the PWM control. The switching arrangement to govern the on and off behavior of the transistors is shown in the control schemes of Figure 4. It has already been stated that the control schemes used in the realization of voltage buck operation can be effectively employed for voltage boost operation. The power flow loops of Figure 7a-d can be used to demonstrate the non-inverted voltage boost behavior for any value of input voltage. 


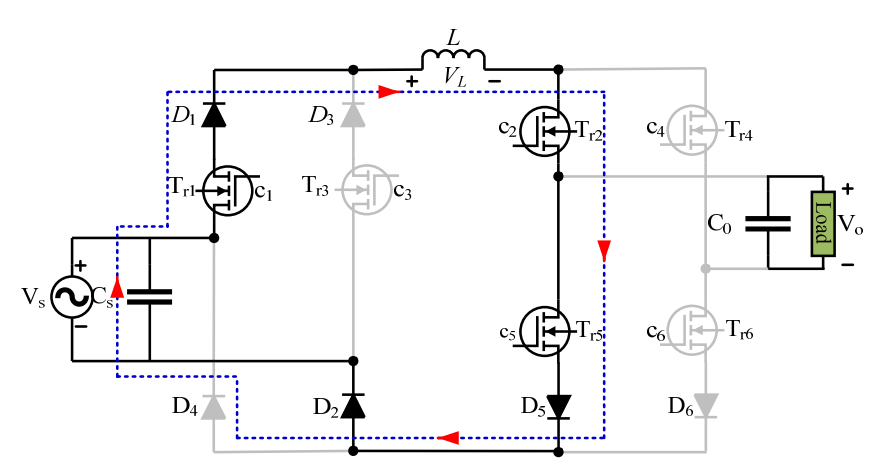

(a)

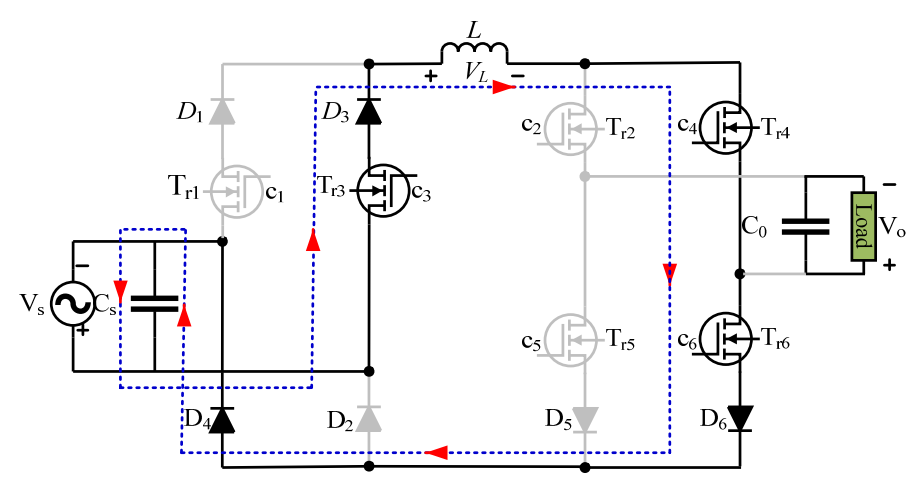

(c)

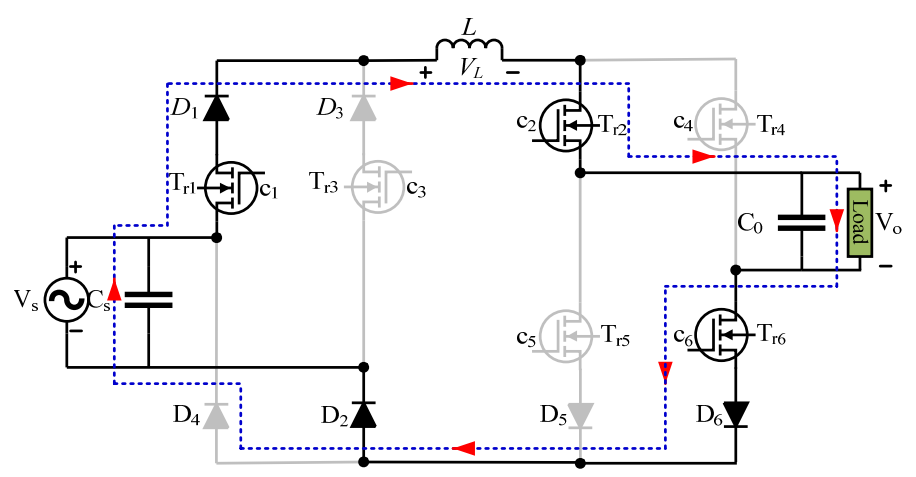

(b)

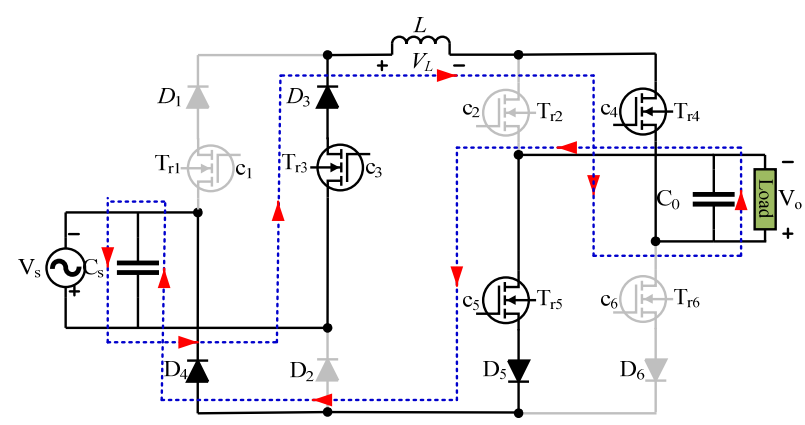

(d)

Figure 7. Equivalent power transfer loops formed by PWM control to have non-inverted voltage boost output for half cycles of $(\mathbf{a}, \mathbf{b})$ positive source voltage; $(\mathbf{c}, \mathbf{d})$ negative source voltage.

For positive input voltage, the PWM control of transistor $T_{r 5}$ stores power in the inductor via the power flowing loop formed by the conduction of $T_{r 1}, D_{1}, T_{r 2}, D_{2}, T_{r 5}$, and $D_{5}$ that may be seen from Figure 7a. In the non-conducting interval of the PWM control, the inductor and source get connected in series with the load through the operating devices $T_{r 1}, D_{1}, T_{r 2}, D_{2}, T_{r 6}$, and $D_{6}$ that may find in the loop of Figure $7 \mathrm{~b}$. Here switching of transistor $T_{r 6}$ during conducting and non-conducting intervals of PWM control ensures the continuous inductor current as series diode $D_{6}$ operates in a complementary way of transistor $T_{r 5}$. A similar operation can be explored for negative input as depicted in the power flow loops of Figure 7c,d. The value of the inductor voltage during the conducting and non-conducting intervals of the PWM control is used to find out the variation in the output voltage with respect to the constant input voltage. That is to say

$$
\begin{gathered}
V_{L}\left(t_{c}\right)=V_{s} \\
V_{L}\left(t_{n c}\right)=V_{s}-V_{o}
\end{gathered}
$$

By finding the average of inductor voltage

$$
\begin{gathered}
V_{s} t_{c}+\left(V_{s}-V_{o}\right) t_{n c}=0 \\
V_{s}\left(t_{c}+t_{n c}\right)=V_{o} t_{n c} \\
V_{s} T=V_{o}(1-D) T \\
V_{o}=\frac{V_{s}}{1-D}
\end{gathered}
$$


The voltage inverting operation can also be supported with the same control signals to generate non-inverting outputs. The conduction of $T_{r 1}, D_{1}, T_{r 4}, D_{2}, T_{r 5}, D_{6}$ and PWM control of $T_{r 6}$ during positive input helps to store power in the inductor, as may be viewed from Figure 8a. Then turning off of $T_{r 6}$ and forward biasing of $D_{5}$ along with previously conducting devices $T_{r 1}, D_{1}, D_{2}, T_{r 4}, T_{r 5}$ connect the source, inductor, and load in series as may be viewed from Figure $8 \mathrm{~b}$. The detail of inverting behavior for negative input may view from the power flow loops of Figure $8 \mathrm{c}, \mathrm{d}$ plotted during the conducting and non-conducting intervals of the PWM control, respectively.

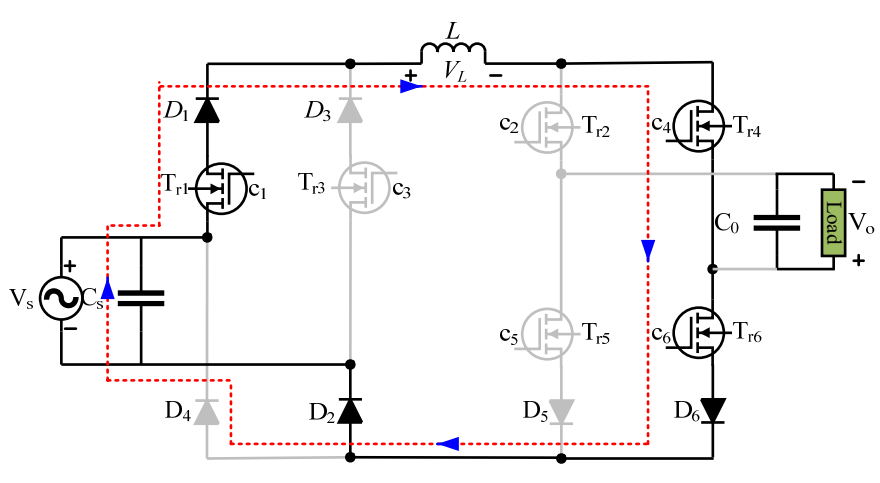

(a)

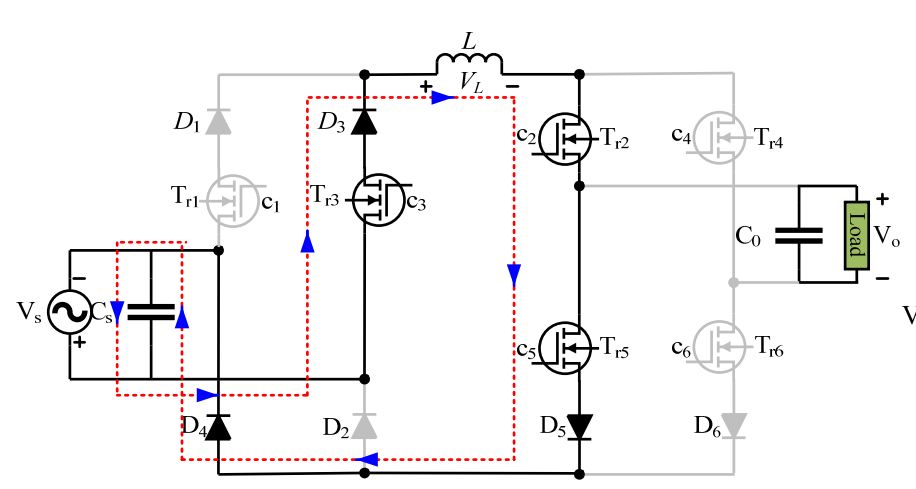

(c)

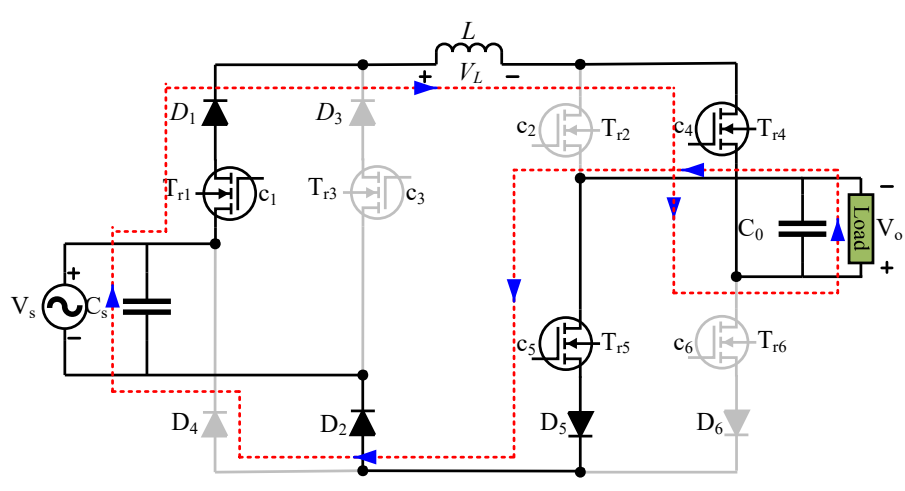

(b)

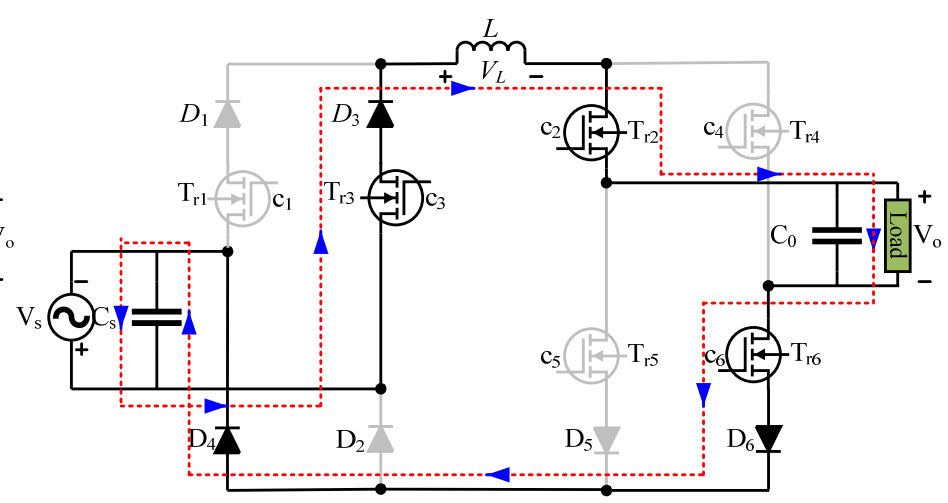

(d)

Figure 8. Equivalent power transfer loops formed by PWM control to have inverted voltage boost output for half cycles of $(\mathbf{a}, \mathbf{b})$ positive source voltage; $(\mathbf{c}, \mathbf{d})$ negative source voltage.

The validation of inverting voltage gains for both input polarities may also be formulated with the help of inductor voltage during the conducting and non-conducting intervals of the PWM control.

$$
\begin{gathered}
V_{L}\left(t_{c}\right)=V_{s} \\
V_{L}\left(t_{n c}\right)=V_{s}+V_{o}
\end{gathered}
$$

Averaging of inductor voltage is

$$
\begin{gathered}
V_{s} t_{c}+\left(V_{s}+V_{o}\right) t_{n c}=0 \\
V_{s}\left(t_{c}+t_{n c}\right)=-V_{o} t_{n c} \\
V_{s} T=-V_{o}(1-D) T \\
V_{o}=\frac{-V_{s}}{1-D}
\end{gathered}
$$


The comparison of Equations (22) and (28) proves stabilization of the bipolar voltage capabilities of the output voltage with PWM or duty cycle control.

\section{Consideration of the Conversion Losses}

The losses in any power converting system depend on the losses caused by the filtering components, solid-state devices, and gate control circuits. Power losses produced by the filtering component can be ignorable as they have a low value of their internal resistances. The losses produced by the solid-state transistors and diodes are the sum of their switching $\left(P_{s w}\right)$ and conduction losses $\left(P_{c o n}\right)$.

The switching losses depend on the switching frequency and the value of the voltages and currents at which they change their states from off to on and vice versa. These losses in transistors are a function of their current and voltage rise and fall characteristics and but in diode, they are related to their reverse recovery characteristics. The instantaneous voltage and currents in any switching period can be considered constant as switching periods are much less than that of the periods of the output or input voltages. The switching losses of a MOSFET and diode may be calculated by considering the procedure developed in [24].

$$
\begin{gathered}
P_{s w(M)}=\frac{1}{6} V_{D S} I_{D S} f_{s}\left(t_{\text {rise }}+t_{\text {fall }}\right) \\
P_{s w(D)}=Q_{R R} V_{R R} f_{s}
\end{gathered}
$$

Here $V_{D S}$ and $I_{D S}$ are the drain to source voltage and current, respectively. The $t_{\text {rise }}$ and $t_{f a l l}$ are the intervals in which the drain current increases to the final steady-state value and decreases to the minimum value, respectively. $Q_{R R}$ is the amount of reverse recovery charge that flows across the junction and $V_{R R}$ is the reverse voltage across the junction during the reverse recovery intervals. The value of the conduction losses for a MOSFET and diode is calculated as

$$
\begin{gathered}
P_{\operatorname{con}(M)}=I_{D S(r m s)}^{2} R_{D S(o n)} \\
P_{c o n(D)}=I_{D(r m s)}^{2} R_{D(o n)}+V_{D} I_{D(a v g)}
\end{gathered}
$$

The conduction losses of a transistor and diode depend on the value of their internal resistances and rms and average currents.

The losses produced by the gate control circuits $\left(P_{G C}\right)$ are the sum of isolated DC supplies and gate drivers. That may be considered constant as they depend on their number. There is a need for only six gate control circuits in the developed topology but the execution of the circuit in [20] requires the use of eight such circuits. There is the conduction of four low-frequency transistors and diodes along with the high-frequency switching operation of two transistors and diodes during one output interval. The total conversion losses of the developed circuit and circuit reported in $[11,20]$ may be approximated as

$$
\begin{gathered}
P_{\text {Losses }[20]}=\frac{V_{D S} I_{D S} f_{s}\left(t_{\text {rise }}+t_{f a l l}\right)}{3}+2 Q_{R R} V_{R R} f_{s}+6\left[I_{D S(r m s)}^{2} R_{D S(\text { on })}+V_{D} I_{D(a v g)}+I_{D(r m s)}^{2} R_{D(\text { on })}\right]+8 P_{G C} \\
P_{\text {Losses [proposed }]}=\frac{V_{D S} I_{D S} f_{s}\left(t_{\text {rise }}+t_{f a l l}\right)}{3}+2 Q_{R R} V_{R R} f_{s}+6\left[I_{D S(r m s)}^{2} R_{D S(\text { on })}+V_{D} I_{D(a v g)}+I_{D(\text { rms })}^{2} R_{D(\text { on })}\right]+6 P_{G C}
\end{gathered}
$$

The elimination of two gate control circuits in the developed circuit not only reduces the conversion losses but also drastically lowers the circuit's overall volume and cost.

\section{Comparative Analysis to Ensure Circuit's Effectiveness}

The use of two transistors and diodes is excluded and this is the main achievement of the developed power converting approach. This attainment helps to compact the overall structure of the system as the size and cost of the gate supporting circuit are much larger than the transistor. The proposed circuit can deliver or govern the bipolar polarity output in buck and boost modes. This capability lowers the voltage and current rating of the 
solid-state devices and improves power quality by lowering the voltage and current ripples. These features are addressed in [20] in detail. The proposed and existing approaches in [11] and [20] uses the conduction of three transistors and the diodes to obtain the output of any of its operating modes, so they have equal losses generated by the solid-state devices. In short, the summary of the comparison of the performance evaluation of the suggested converter and existing topologies operated with a similar approach are summarized in Tables 1 and 2 for voltage step-down and step-up operation for voltage gain of 0.5 and 2, respectively.

Table 1. Comparison of the performance evaluation for inverting voltage step-down output considering a factor of 0.5 .

\begin{tabular}{cccc}
\hline Parameters & Suggested Converter & Converter In [20] & Converter In [11] \\
\hline Peak inductor ripple current & $0.25\left(\frac{V_{s(\max )}}{L}\right) T$ & $0.25\left(\frac{V_{s(\max )}}{L}\right) T$ & $0.334\left(\frac{V_{s(\max )}}{L}\right) T$ \\
Peak value of current & $I_{o(\max )}$ & $I_{o(\max )}$ & $1.5 I_{o(\max )}$ \\
Peak value of voltage & $V_{s(\max )}$ & $V_{s(\max )}$ & $1.5 V_{s(\max )}$ \\
Count of transistors & 6 & 8 & 6 \\
Count of diodes & 6 & 8 & 6 \\
Count of gate supporting circuit & 6 & 8 & 6 \\
Count of isolated DC sources & 6 & 6 \\
\hline
\end{tabular}

Table 2. Comparison of the performance evaluation for inverting voltage step-up output considering a factor of 2.

\begin{tabular}{cccc}
\hline Parameters & Suggested Converter & Converter In [20] & Converter In [11] \\
\hline Peak inductor ripple current & $0.5\left(\frac{V_{s(\max )}}{L}\right) T$ & $0.5\left(\frac{V_{s(\max )}}{L}\right) T$ & $0.667\left(\frac{V_{s(\max )}}{L}\right) T$ \\
Peak value of current & $2 I_{o(\max )}$ & $2 I_{o(\max )}$ & $3 I_{o(\max )}$ \\
Peak value of voltage & $2 V_{s(\max )}$ & $2 V_{s(\max )}$ & $3 V_{s(\max )}$ \\
Count of transistors & 6 & 8 & 6 \\
Count of diodes & 6 & 8 & 6 \\
Count of gate supporting circuit & 6 & 8 & 6 \\
Count of isolated DC sources & 6 & 8 & 6 \\
\hline
\end{tabular}

\section{Design Description}

The basic purpose of using the input and output capacitance is to eliminate the unwanted voltage components. On the other hand, the role of the inductor is to minimize the ripple contents in the current. The inductor is also used as an energy-storing element and helps to tackle the shoot-through issue as well. The design of these elements depends on the input voltage $\left(V_{S}\right)$, average value of the inductor current $\left(I_{L}\right)$, output current $\left(I_{o}\right)$ or impedance $\left(Z_{L}\right)$, switching frequency $\left(f_{s}\right)$, inductor ripple current factor $\left(k_{i}\right)$ that is normally $20 \%$ of inductor current and output voltage ripple factor $\left(k_{v}\right)$ that may take $10 \%$ of the output or input voltage. The role of the developed circuit is to step down and step up the input voltage at the output. The design of the filtering components is obtained with respect to the high value of the voltage and currents of the developed circuit. In voltage buck operation, the average value of the inductor and output currents are the same but in boost mode, the average value of the inductor is greater than the average output current with the relation given in Equation (35). The value of the duty cycle and switching frequency is taken 0.5 and $25 \mathrm{kHz}$, respectively. The values of the filtering components are computed with a similar approach stated in $[19,25]$.

$$
I_{L}=\frac{I_{o}}{(1-D)}
$$

The value of the inductor is calculated for an input voltage of $65 \mathrm{~V}$, a duty cycle of $D=0.5$, a switching frequency of $25 \mathrm{kHz}$, and a maximum value of the inductor current of 2 A. 


$$
L=\frac{V_{s} D(1-D)}{k_{i} I_{L} f_{s}}=0.8125 \mathrm{mH}
$$

The ripples in the output voltage are directly related to the value of the output capacitance whose value is computed for an output voltage of $65 \mathrm{~V}$ and output current of $1 \mathrm{~A}$ as

$$
C_{o}=\frac{D I_{o}}{k_{v} V_{o} f_{s}}=3.07 \mu \mathrm{F}
$$

The value of the input capacitance depends on the duration in which it is discontinuous. The input current is continuous in voltage boost mode and is only discontinuous in voltage buck mode. Its value is calculated with an input current of $0.5 \mathrm{~A}$ as

$$
\therefore C_{\text {in }}=\frac{I_{s}(1-D)}{k_{v} V_{s} f_{s}}=1.5 \mu \mathrm{F}
$$

So, the values of the inductor and output and input capacitance are approximated for computer and practical results as $1 \mathrm{mH}, 4.7 \mu \mathrm{F}$ and $1 \mu \mathrm{F}$, respectively.

\section{Results}

Validation of the developed circuit is confirmed with the help of results attained from computer simulation and practical setup. Their detail is expressed with the help of plots of input and output voltage. The plots of voltage across the high-frequency solid-state devices also confirm the effectiveness of the suggested circuit, indicating low maximum break overvoltage.

\subsection{Computer Simulation-Based Results}

In this analysis, Matlab software is preferred for computer simulation results as it is very attractive and powerful in the field of switching converters. For both operations (non-inverted and inverted) of the voltage step-down capabilities, the input rms voltage is chosen $50 \mathrm{~V}$ (70 volts peak). The pulse width or duty ratio of the PWM control is set to $50 \%$ to obtain an output rms voltage of $25 \mathrm{~V}$ ( 35 volts peak). For this purpose, the diode is modeled with a $0.8 \mathrm{~V}$ internal drop, and the value of internal resistance of a transistor is set to $85 \mathrm{~m} \Omega$. Two capacitors with the values of $1 \mu \mathrm{F}$ and $4.7 \mu \mathrm{F}$ are connected at input and output, respectively, to block the unwanted harmonics or ripples. Additionally, an inductor of $1 \mathrm{mH}$ is used as a filtering and energy storing element. Its presence also helps to avoid the circuit complications resulting from shoot through. The plots of Figure $9 \mathrm{a}, \mathrm{b}$ show that output voltage (red plot) has the same and opposite phase with respect to input voltage's polarity (blue plot) confirming voltage in-phase and out-phase operation. In the voltage buck process, the maximum voltage value across the PWM control devices cannot exceed the input voltage level, and this point is conformed from Figure 10a,b, where this level is almost $70 \mathrm{~V}$.

The voltage plots of converter operation in which the required voltage is greater than the input level are demonstrated in Figure 11.

In this operation, the target is to confirm the voltage boost characteristics. For this purpose, the input $25 \mathrm{~V}$ rms voltage (plotted in blue color) is step up to $50 \mathrm{~V}$ rms level (plotted in red color) with a duty cycle control of 50\%. The plots of Figure $11 \mathrm{a}, \mathrm{b}$ confirm the voltage boost capabilities for both polarities at the output. Moreover, the plots of Figure $12 \mathrm{a}, \mathrm{b}$ prove that the voltage of the high switching transistors is not able to exceed the level of the output voltage.

The correction of the grid voltage is one of the key applications of the developed circuit. This circuit can tackle the issue of voltage sag or swell having any voltage depth level as it has the ability to buck or boost the input voltage at the output with dual polarity. A commonly occurring event in a power distribution system is voltage sag and most of the time its depth level is less than $50 \%$. The pulse width or duty cycle to produce the required compensating voltage depends on the level of the correcting voltage. The voltage gain of 
the voltage correcting circuit is larger than unity if correcting voltage level is more than $50 \%$. This forces the correcting circuit in voltage boost mode. If the level of the correcting voltage is less than $50 \%$, then the required voltage is less than unity. In this case, the voltage correcting circuit operates in buck mode. Figure 13 shows the compensation of the voltage for various level voltage sag problems.

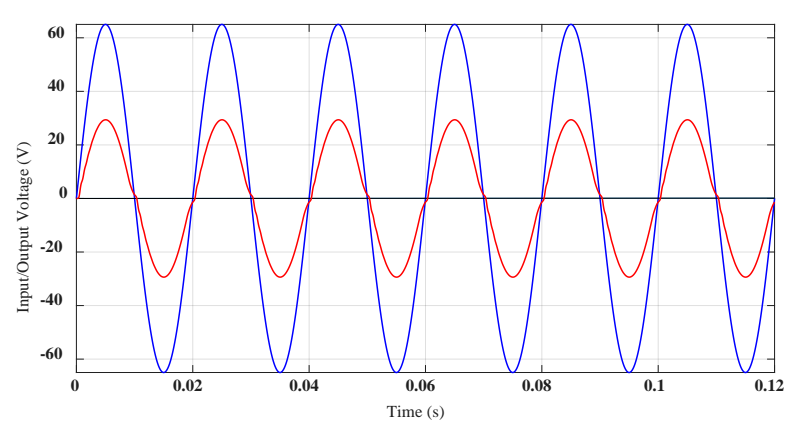

(a)

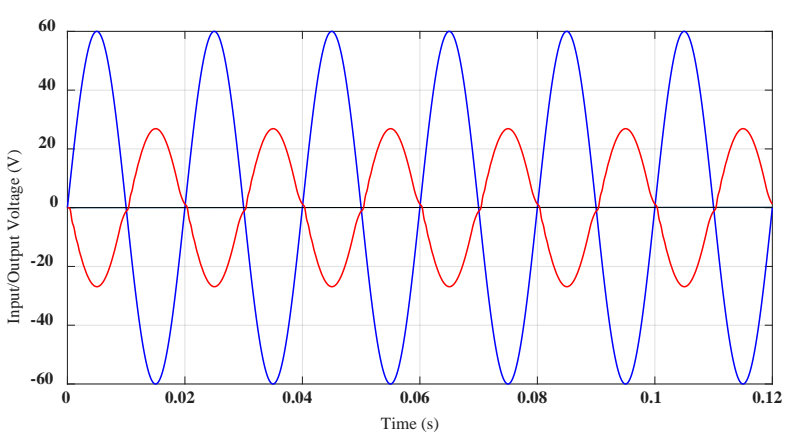

(b)

Figure 9. Computer simulation results of output voltage (red) with respect to input (blue) for output step-down process in (a) non-inverted form and (b) inverted form.
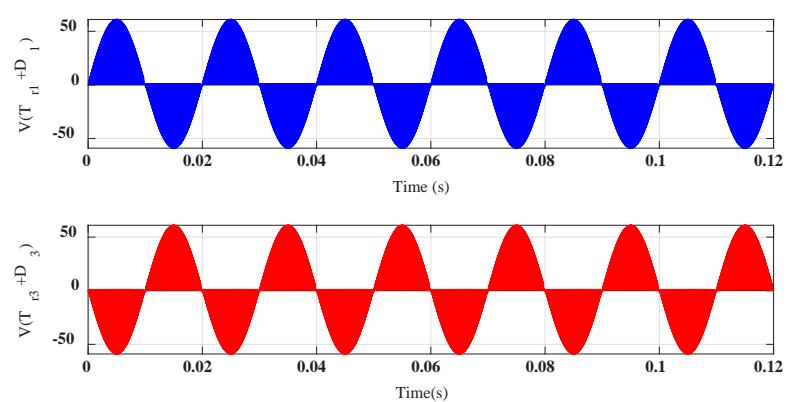

(a)
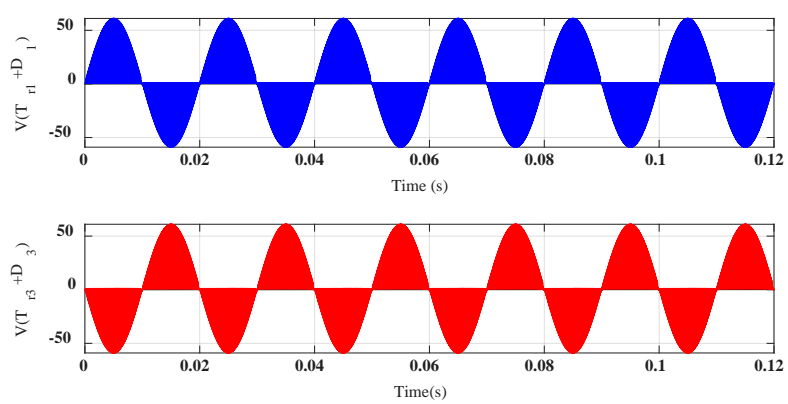

(b)

Figure 10. Computer simulation results for output step-down process across $T_{r 1}, D_{1}$ (blue) and $T_{r 3}, D_{3}$ (red) in (a) noninverted form and (b) inverted form.

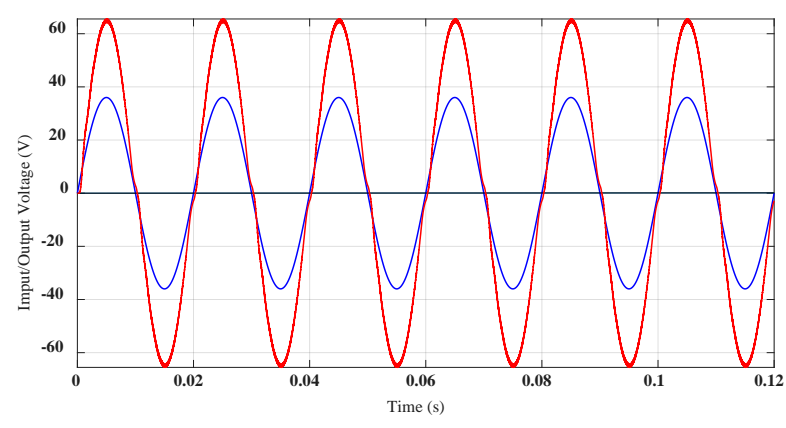

(a)

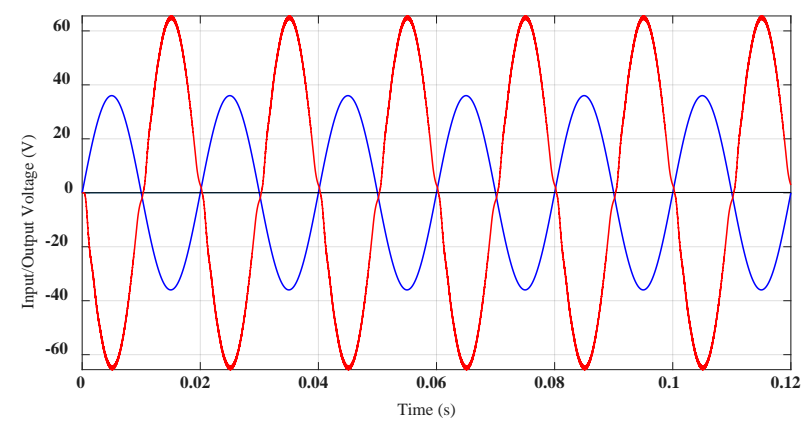

(b)

Figure 11. Computer simulation results of output voltage (red) with respect to input (blue) for output step-up process in (a) non-inverted form and (b) inverted form. 

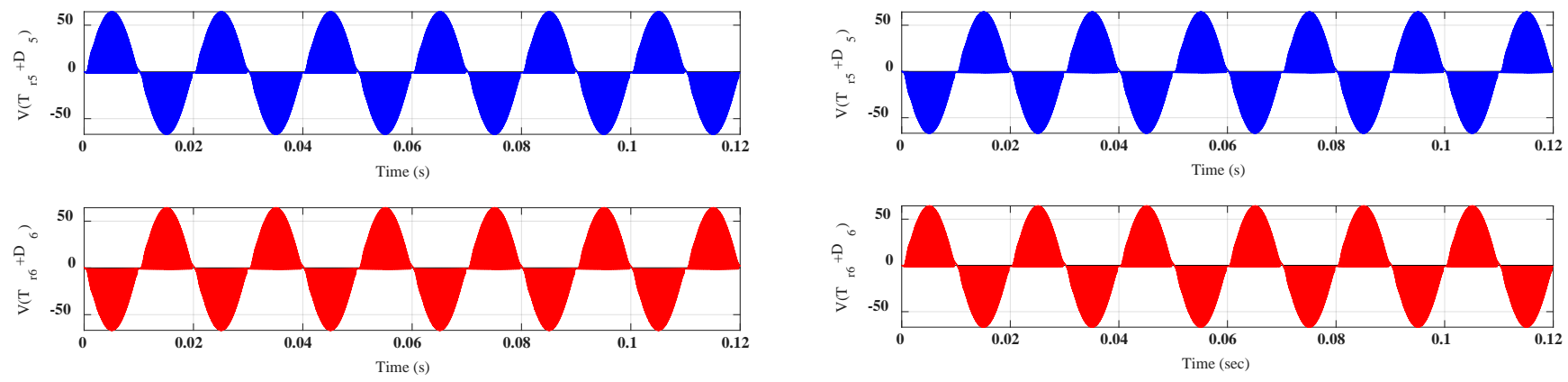

(a)

(b)

Figure 12. Computer simulation results for output step-up process across $T_{r 5}, D_{5}$ (blue) and $T_{r 6}, D_{6}$ (red) in (a) non-inverted form and (b) inverted form.

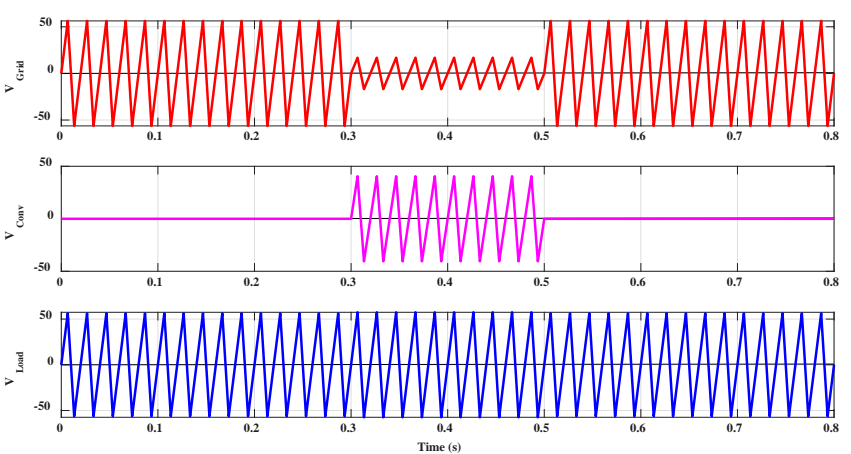

(a)
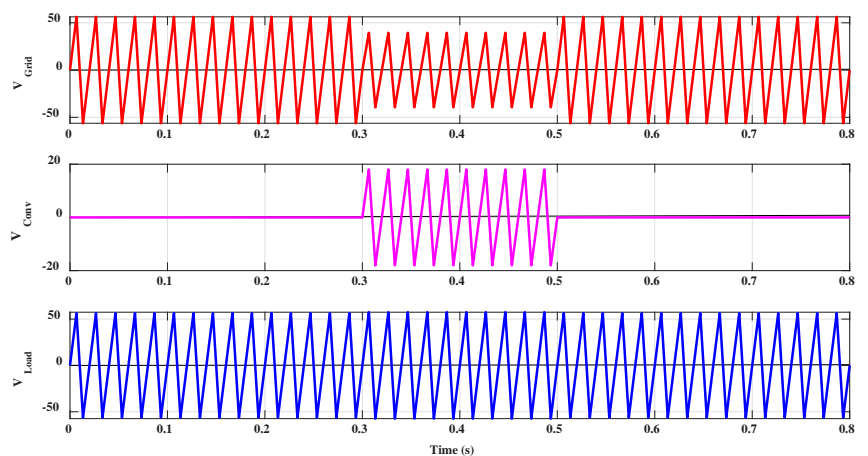

(b)

Figure 13. Computer simulation results for the compensation of voltage sag for depth level of (a) $70 \%$ and (b) $30 \%$.

\subsection{Practical Results}

The verification of the computer simulation results is carried by developing a hardware setup with the help of six diodes (RHRG3040) and six transistors (IRF840). The on and off control of a transistor is achieved with a gate supporting circuit that utilizes EXB840 hybrid chip and isolated DC voltage as the main sources. The size of the gate supporting circuit is not comparable to the overall size of six diodes and transistors. The use of input capacitor $(1 \mu \mathrm{F})$ and output capacitor $(4.7 \mu \mathrm{F})$ enhances the power quality by suppressing the unwanted components. An inductor of $1 \mathrm{mH}$ reduces the current ripple to enhance its power quality. It stores and releases the power during conducting and non-conducting intervals of PWM control that is a mandatory requirement of voltage step up and down operation. The six gate supporting circuits facilitate the on and off operation of the six transistors. A high-speed signal STM controller produces the required control outputs. These signals have to match with the change in the polarity of the source voltage. This task is achieved by employing the sensing circuit for input polarity detection. The low power output control signals of the STM controller are connected to the six transistor's driving circuits that take the power from six DC sources for the amplification purpose. These outputs of these DC sources are isolated with respect to one another and also with respect to line voltage as this is realized by employing six low-frequency step-down transformers. The output control signals of gate supporting circuits have similar characteristics as generated by the STM controller, but their voltage level is increased to $12 \mathrm{~V}$ to $15 \mathrm{~V}$ (output level of the DC sources).

The waveforms of input and output voltage obtained from this setup with the help of an oscilloscope are demonstrated in Figure 14a,b, validating non-inverted and inverted 
buck capabilities. Here the red color of input differentiates the output that is plotted with blue color.

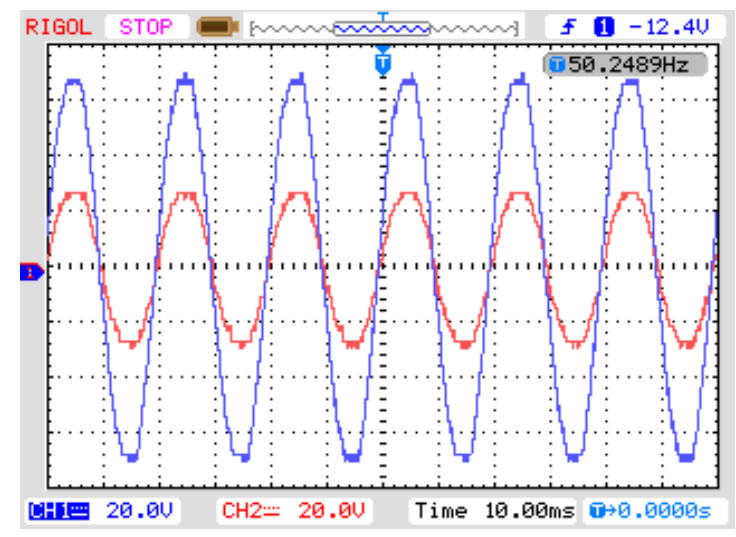

(a)

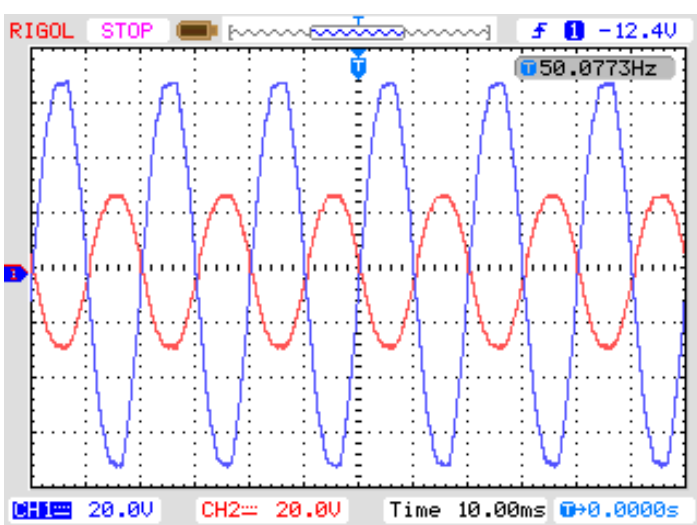

(b)

Figure 14. Practically obtained results of output voltage (red) with respect to input voltage (blue) for output step-down process in (a) non-inverted form and (b) inverted form.

Figure 15a,b confirm the result of Figure $10 \mathrm{a}, \mathrm{b}$ in the simulation section. The confirmation of voltage boost capabilities is confirmed by the plots of Figures 16 and 17 for output voltage and the voltage across the transistors operated at high frequencies. All the practical results prove the validity of the computer simulation section and input-output analysis of the operational modes.

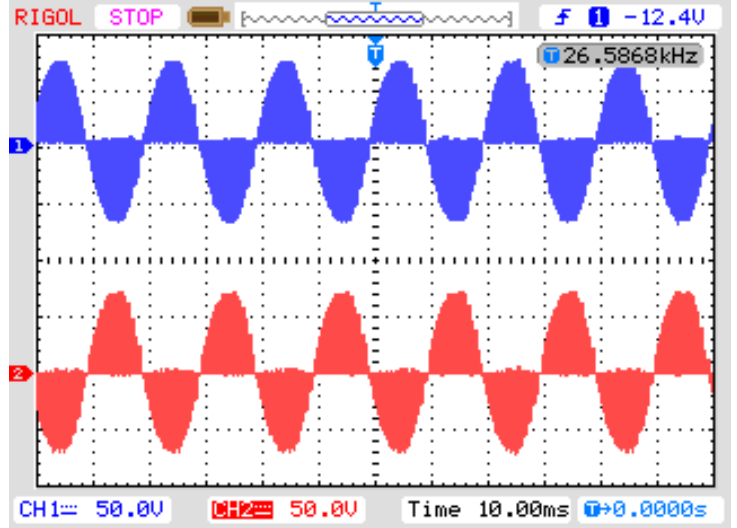

(a)

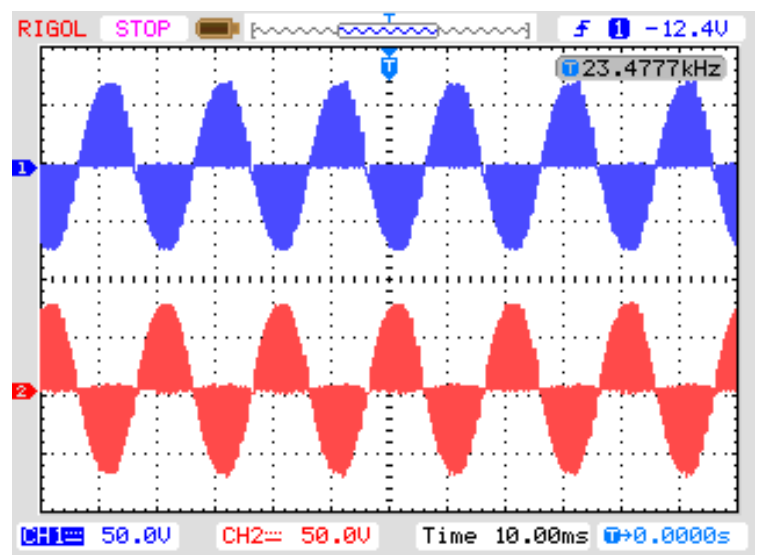

(b)

Figure 15. Practically obtained results for output step-down process across $T_{r 1}, D_{1}$ (blue) and $T_{r 3}, D_{3}$ in (a) non-inverted form and (b) inverted form. 


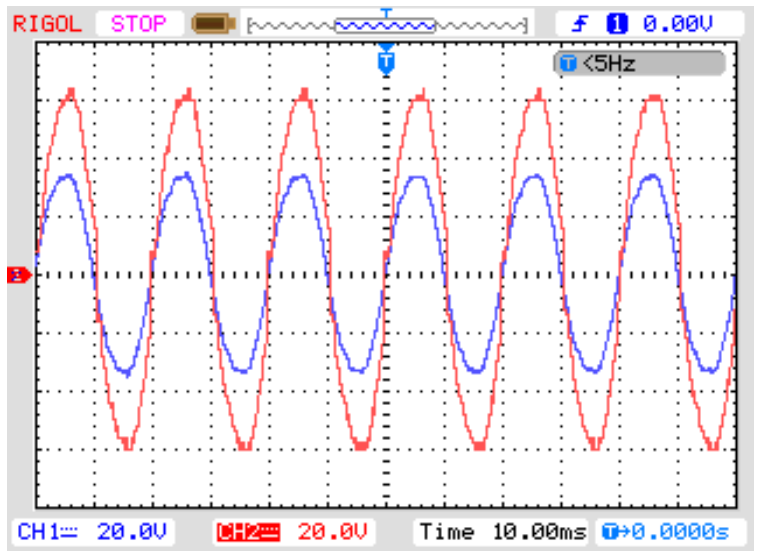

(a)

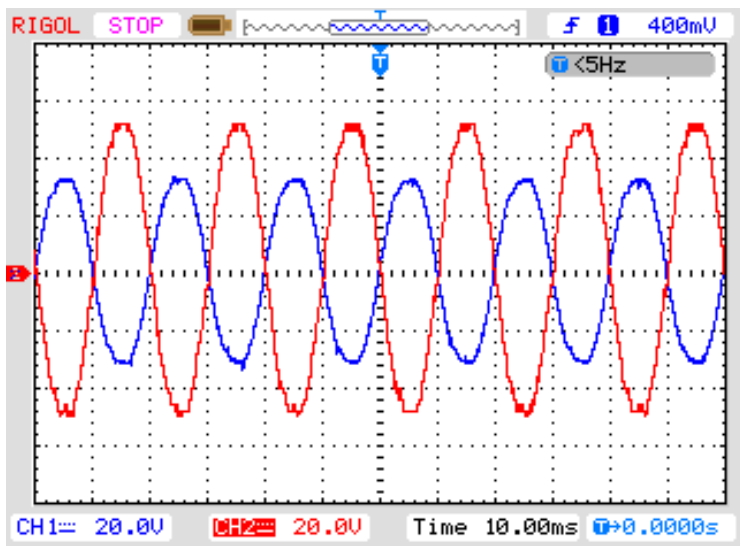

(b)

Figure 16. Practically obtained results of output voltage (red) with respect to input (blue) for output step-up process in (a) non-inverted form and (b) inverted form.

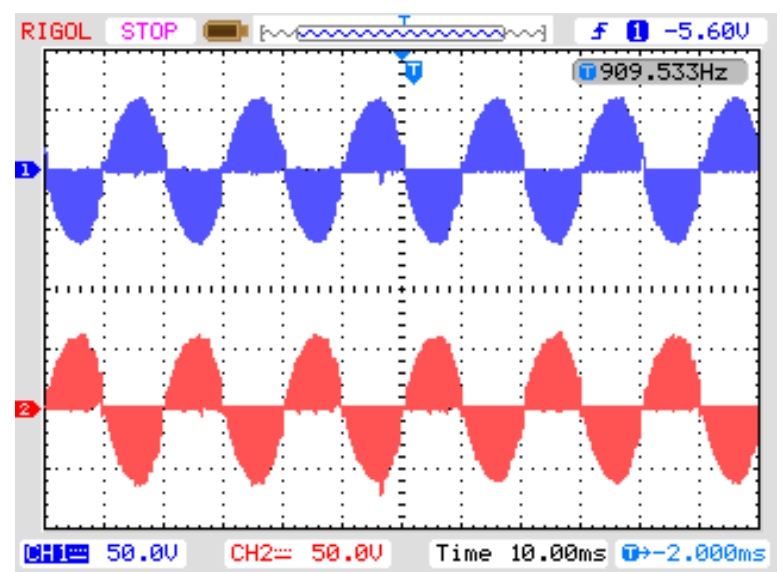

(a)

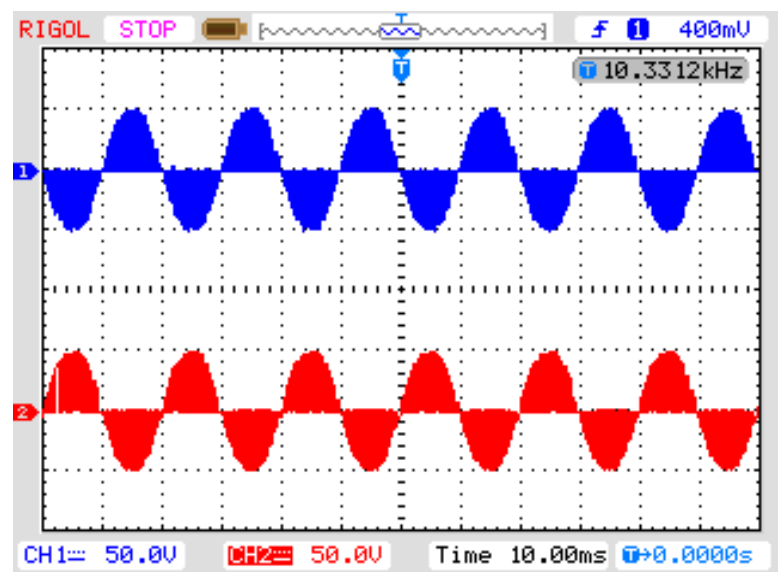

(b)

Figure 17. Practically obtained results for output step-up process across $T_{r 5}, D_{5}$ (blue) and $T_{r 6}, D_{6}$ (red) in (a) non-inverted form and (b) inverted form.

\section{Conclusions}

This research article presents a bipolar voltage gain controller covering the complete range of voltage regulation with a PWM control scheme. The developed controller has the capability to increase or decrease the output voltage for any polarity with respect to the input voltage. The development of the proposed circuit requires the use of only six transistors and six diodes. The use of a number of transistors is the key feature for determining the size and cost of the power converter's circuit. The switching behavior of the transistors whose reference terminals (source terminal for MOSFET) are not connected to the circuit's common point is highly dependent on the use of gate supporting circuits along with separate DC source. The size and cost of such circuit arrangement are much larger than that of the operating transistors. The elimination of two transistors compared to the existing circuits effectively lowers the overall size and cost. To support the validity of the developed circuit, the results obtained from computer modeling and practical circuit are compared, expressing good agreement. 
Author Contributions: Conceptualization, N.A. and G.A.; data curation, G.A. and N.U.; formal analysis, N.A., A.N.A. and U.F.; funding acquisition, N.U. and A.R.; investigation, N.A. and M.T.R.; methodology, G.A. and A.R.; project administration, G.A.; resources, A.N.A. and N.U.; software, U.F. and M.T.R.; validation, U.F. and M.T.R.; writing-original draft, N.A. and G.A.; writing-review and editing, G.A., A.N.A., A.R. and N.U. All authors have read and agreed to the published version of the manuscript.

Funding: This research received no external funding.

Institutional Review Board Statement: Not applicable.

Informed Consent Statement: Not applicable.

Data Availability Statement: Not applicable.

Acknowledgments: The authors are thankful to Taif University, Saudi Arabia, and The University of Lahore, Pakistan for providing the facilities to conduct this research.

Conflicts of Interest: The authors declare no conflict of interest.

\section{References}

1. Subramanian, S.; Mishra, M.K. Interphase AC-AC Topology for Voltage Sag Supporter. IEEE Trans. Power Electron. 2010, 25, 514-518. [CrossRef]

2. Lodetti, S.; Azcarate, I.; Gutiérrez, J.J.; Leturiondo, L.A.; Redondo, K.; Sáiz, P.; Melero, J.J.; Bruna, J. Flicker of modern lighting technologies due to rapid voltage changes. Energies 2019, 12, 865. [CrossRef]

3. Ashraf, N.; Izhar, T.; Abbas, G.; Awan, A.B.; Farooq, U.; Balas, V.E. A New Single-Phase AC Voltage Converter with Voltage Buck Characteristics for Grid Voltage Compensation. IEEE Access 2020, 8, 48886-48903. [CrossRef]

4. Ashraf, N.; Abbas, G.; Ullah, N.; Alkhammash, H.I.; Zubair, M. An Improved Bipolar Voltage Boost AC Voltage Controller with Reduced Switching Transistors. IEEE Access 2021, 9, 90402-90417. [CrossRef]

5. Abas, N.; Dilshad, S.; Khalid, A.; Saleem, M.S.; Khan, N. Power Quality Improvement Using Dynamic Voltage Restorer. IEEE Access 2020, 8, 164325-164339. [CrossRef]

6. Bastos, A.F.; Lao, K.; Todeschini, G.; Santoso, S. Accurate Identification of Point-on-Wave Inception and Recovery Instants of Voltage Sags and Swells. IEEE Trans. Power Deliv. 2019, 34, 551-560. [CrossRef]

7. de Paula Dias Queiroz, A.; Jacobina, C.B.; de Freitas, N.B.; Maia, A.C.N.; Melo, V.F.M.B. Single-Phase AC-DC-AC Multilevel Converter Based on H-Bridges and Three-Leg Converters Connected in Series. IEEE Trans. Ind. Appl. 2018, 54, 4696-4706. [CrossRef]

8. Li, L.; Wu, M.; Wu, S.; Li, J.; Song, K. A Three-Phase to Single-Phase AC-DC-AC Topology Based on Multi-Converter in AC Electric Railway Application. IEEE Access 2019, 7, 111539-111558. [CrossRef]

9. da Costa, A.E.L.; Rocha, N.; Jacobina, C.B.; Fabricio, E.L.L. Single-Phase AC-DC-AC Three-Level Three-Leg Converter with Reduced Switch Count. IEEE Trans. Power Electron. 2020, 35, 2295-2307. [CrossRef]

10. de Lacerda, R.P.; Jacobina, C.B.; Fabricio, E.L.L.; Rodrigues, P.L.S. Six-Leg Single-Phase AC-DC-AC Multilevel Converter with Transformers for UPS and UPQC Applications. IEEE Trans. Ind. Appl. 2020, 56, 5170-5181. [CrossRef]

11. Ahmed, H.F.; Cha, H.; Khan, A.A.; Kim, H. A Novel Buck-Boost AC-AC Converter with Both Inverting and Noninverting Operations and without Commutation Problem. IEEE Trans. Power Electron. 2016, 31, 4241-4251. [CrossRef]

12. Ashraf, N.; Abbas, G.; Abbassi, R.; Jerbi, H. Power Quality Analysis of the Output Voltage of AC Voltage and Frequency Controllers Realized with Various Voltage Control Techniques. Appl. Sci. 2021, 11, 538. [CrossRef]

13. Jothibasu, S.; Mishra, M.K. An Improved Direct AC-AC Converter for Voltage Sag Mitigation. IEEE Trans. Ind. Electron. 2015, 62, 21-29. [CrossRef]

14. He, L.; Nai, J.; Zhang, J. Single-Phase Safe-Commutation Trans-Z-Source AC-AC Converter with Continuous Input Current. IEEE Trans. Ind. Electron. 2017, 65, 5135-5145. [CrossRef]

15. Ahmed, H.F.; Cha, H. A New Class of Single-Phase High-Frequency Isolated Z-Source AC-AC Converters with Reduced Passive Components. IEEE Trans. Power Electron. 2018, 33, 1410-1419. [CrossRef]

16. Aleem, Z.; Yang, H.-K.; Ahmed, H.F.; Winberg, S.L.; Park, J.-W. A Class of Single-Phase Z-Source AC-AC Converters with Magnetic Coupling and Safe-Commutation Strategy. IEEE Trans. Ind. Electron. 2021, 68, 8104-8115. [CrossRef]

17. SSharifi; Jahani, F.; Monfared, M. Direct Single-Phase AC-AC Converters Based on Series Impedance Networks. IEEE Trans. Power Electron. 2018, 33, 10380-10389. [CrossRef]

18. Khan, A.A.; Cha, H.; Ahmed, H.F. High-Efficiency Single-Phase AC-AC Converters without Commutation Problem. IEEE Trans. Power Electron. 2016, 31, 5655-5665. [CrossRef]

19. Ashraf, N.; Izhar, T.; Abbas, G. A single-phase buck-boost matrix converter with low switching stresses. Math. Probl. Eng. 2019, 2019, 6893546. [CrossRef]

20. Ashraf, N.; Izhar, T.; Abbas, G.; Balas, V.E.; Balas, M.M.; Lin, T.-C.; Asad, M.U.; Farooq, U.; Gu, J. A Single-Phase Buck and Boost AC-to-AC Converter with Bipolar Voltage Gain: Analysis, Design, and Implementation. Energies 2019, 12, 1376. [CrossRef] 
21. Yang, Z.; Ye, S.; Liu, Y. A New Resonant Gate Drive Circuit for Synchronous Buck Converter. IEEE Trans. Power Electron. 2007, 22, 1311-1320. [CrossRef]

22. Wu, Q.; Wang, Q.; Zhu, J.; Lan, X. Dual-Channel Push-Pull Isolated Resonant Gate Driver for High-Frequency ZVS Full-Bridge Converters. IEEE Trans. Power Electron. 2019, 34, 4019-4024. [CrossRef]

23. Ashraf, N.; Abbas, G.; Ullah, N.; Otaibi, S.A.; Althobaiti, A.; Zubair, M.; Farooq, U. A Bipolar Voltage Gain Boost AC-AC Converter Based on Four Switching Transistors. Appl. Sci. 2021, 11, 10254. [CrossRef]

24. Jung, H.Y.; Kim, S.H.; Moon, B.; Lee, S. A New Circuit Design of Two-Switch Buck-Boost Converter. IEEE Access 2018, 6, 47415-47423. [CrossRef]

25. Li, P.; Hu, Y. Unified Non-Inverting and Inverting PWM AC-AC Converter with Versatile Modes of Operation. IEEE Trans. Ind. Electron. 2017, 64, 1137-1147. [CrossRef] 